\title{
A Alimentação e a Dieta Alimentar no Gerenciamento da Condição Crônica do Diabetes'
}

Food and Diet in the Diabetes Chronic Condition

\section{Management}

\author{
Reni Aparecida Barsaglini \\ Doutora em Saúde Coletiva. Docente do Instituto de Saúde Coletiva \\ da Universidade Federal de Mato Grosso. \\ Endereço: Av. Fernando Correa da Costa, s/n, Bloco CCBS III, CEP \\ 78060-900, Cuiabá, MT, Brasil. \\ E-mail: renibळterra.com.br \\ Ana Maria Canesqui \\ Doutora em Ciências. Professora livre-docente. Adjunta do Depar- \\ tamento de Medicina Preventiva e Social da Faculdade de Ciências \\ Médicas da Universidade Estadual de Campinas. \\ Endereço: Cidade Universitária "Zeferino Vaz", Distrito Barão Ge- \\ raldo, Caixa Postal: 6III, CEP 13083-970, Campinas, SP, Brasil. \\ E-mail: anacanesquiळuol.com.br \\ I Este trabalho é parte da pesquisa de doutorado intitulada \\ Pensar, vivenciar e lidar com o diabetes (defendida em 2006,) \\ desenvolvida junto ao Programa de Pós-graduação em Saúde \\ Coletiva da Universidade Estadual de Campinas, orientada pela \\ Profa. Dra. Ana Maria Canesqui, com financiamento pelo CNPq \\ (processo no. 470043/2006-7) e apoio da Secretaria de Estado \\ de Saúde de Mato Grosso.
}

\section{Resumo}

Objetivo: analisar os aspectos materiais e simbólicos da alimentação e das dietas envolvidos no gerenciamento do diabetes entre adoecidos usuários de serviços públicos de atenção básica. Metodologia: estudo qualitativo pautado pelas representações sociais e a experiência em aspectos do gerenciamento da enfermidade, envolvendo o manejo da alimentação e das dietas alimentares entre homens e mulheres com diabetes tipo II e seus familiares, residentes em município do interior paulista, atendidos por serviços de atenção básica. Os dados foram coletados mediante entrevistas com roteiro semiestruturado e a análise temática identificou as estruturas de relevância, os valores de referência e formas de ação relatados e subjacentes aos relatos, analisados segundo os propósitos do estudo e cotejados com bibliografia especializada. Resultados: no processo de gerenciamento do diabetes, o manejo das dietas e da alimentação pelos adoecidos não se dissocia das representações e da experiência da enfermidade, sendo orientado por ideias, crenças e pelo conjunto de ajustes e microdecisões cotidianas para controlar os efeitos/sensações desfavoráveis permitindo conviver com e apesar dela. As formas de manejar a alimentação e as dietas alimentares são componentes importantes do controle do diabetes, subtraídas do poder exclusivo dos saberes e das práticas médica e nutricional. Conclusão: o manejo das dietas e da alimentação no gerenciamento da condição crônica é complexo, envolvendo aspectos relacionados às condições objetivas de vida, às dimensões socioculturais, valorativas e ideativas, 
que permeiam as representações e as experiências dos adoecidos, inserindo-se na totalidade de suas vidas, relações sociais e nas características de seu grupo social.

Palavras-chave: Diabetes mellitus; Dieta; Alimentação; Pesquisa qualitativa.

\section{Abstract}

Objective: to analyze the material and symbolic aspects of the food and diet involved in the management of diabetes among ill people assisted by primary care services. Methodology: this qualitative study was based on social representations and experience in the management of the disease. It involved the handling of food and diet among men and women diagnosed with type II diabetes and their families, living in a city in the state of São PauloBrazil, users of the primary care services. The data were collected through semi-structured interviews and the thematic analysis identified structures of relevance, reference values and ways of action both reported and underlying the reports, which were analyzed in light of the purposes of the study and compared to the specialized literature. Results: in the management of diabetes, the handling of food and diet by the ill people is not separate from the disease representations and experience, which are oriented by ideas, beliefs and by a set of daily adjustments and micro-decisions in order to control the adverse effects of the disease so that it is possible to live with and despite this condition. The ways of managing the food and diet are important components of diabetes control, extracted from the exclusive power of knowledge and medical and nutritional practices. Conclusion: the handling of food and diet in the chronic condition management is complex, involving issues related to the objective life conditions, socio-cultural dimensions, values and ideations, which permeate the ill people's representations and experience, being inserted in their life, social relations and in the characteristics of their social group.

Keywords: Diabetes Mellitus; Diet; Food; Qualitative Research. 


\section{Introdução}

As condições crônicas constituem agravos persistentes e prolongados que requerem e demandam cuidados permanentes e similares (Organização Mundial da Saúde, 2003), trazendo consequências nos planos individual, coletivo, médico-assistencial e sanitário, que desafiam a ação dos profissionais e do sistema de saúde.

O diabetes integra as condições crônicas e conviver com ele envolve um processo de gerenciamento que pressupõe o impacto da enfermidade na vida dos adoecidos, efetivando-se em esforços nos planos individual (subjetivo), relacional, cultural (significados e identidade), material (condições socioeconômicas) e no manejo da enfermidade; associados à experiência para compreender e "controlar" a situação de modo a viver tão normalmente quanto possível. Essas medidas envolvem, portanto, aspectos sociais, culturais, práticos, ideativos e contextuais (Thorne e col., 2003; Maclean, 1991).

Nesse sentido, o gerenciamento da doença associa-se ao controle como categoria central à experiência de ser diabético, significando uma forma de viver com a condição crônica que envolve ajustamentos (Naemiratch e Manderson, 2006) e autorregulação (Conrad, 1985) empreendidos pelos adoecidos. Essas noções se distinguem da "adesão" ou "aderência" ao tratamento, remetidas às preocupações com os resultados e a eficácia das intervenções, que, quando assentadas na relação terapêutica médica ou no aconselhamento nutricional, enfatizam os desvios ou as resistências dos adoecidos às prescrições, mostrando-se inadequadas ao controle da condição crônica do diabetes.

Não obstante, a relevância do controle dessa enfermidade é reconhecida tanto pelos profissionais de saúde quanto pelas pessoas adoecidas e seus pontos-chave - representados pela tríade medicamento, dieta, prática de exercícios físicos - adquirem significados diferentes para ambos os grupos. Se para os primeiros há uma preocupação técnica com o controle do nível de glicose dentro de padrões de referência (Cohen e col., 1994) e o seguimento das prescrições médicas e dietéticas, os últimos norteiam-se por questões práticas e simbólicas referidas aos contextos culturais, sociais e familiares, que os incitam a promover ajustes nos padrões das prescrições que viabilizem o sentir-se física e moralmente bem em relação ao adoecimento (Barsaglini, 2008).

Longe de depender exclusivamente de vontade autônoma dos adoecidos ou de suas características de personalidade, esses ajustes decorrem da multiplicidade de elementos internos e externos ao sujeito disponíveis no seu contexto sociocultural, mas que serão apropriados diferentemente devido aos seus posicionamentos sociais desiguais na estrutura social, às intermediações culturais, simbólicas, relacionais e situacionais e às singularidades da trajetória pessoal (Adam e Herzlich, 2001) e da experiência com a condição crônica do adoecimento.

É o que ocorre também com a alimentação² que guarda uma função material e vital por prover (ao lado do repouso) as energias à recuperação e à manutenção das condições físicas empregadas nas atividades diárias, mas que transcende as necessidades biológicas, configurando-se como componente das condições objetivas e materiais de vida, ao lado da sociabilidade com implicações relacionais intermediadas pela cultura (Canesqui, 2005). Contudo, o fator cultural (princípios, costumes, valores, significados compartilhados e transmitidos tradicionalmente) não se coloca de forma determinística ou isolada, mas situado e afetado por um contexto particular composto de elementos históricos, econômicos, sociais, políticos e geográficos da sociedade mais ampla (Frankenberg, 1980;Anderson, 1991).

Dessa forma, a relação do adoecido com o alimento, a alimentação e as dietas alimentares prescritas, incluídas no gerenciamento do diabetes, não se pautam exclusivamente por critérios racionais, como pretendem os saberes médico e nutricional científicos ocupados mais com os conteúdos funcionais da "nutrição" do que com a "comida" que, segundo Garcia (2005), recupera elementos da experiência pessoal e social do consumo de alimentos.

Diante disso, este artigo analisa os aspectos materiais e simbólicos da alimentação e da dieta

2 No contexto deste artigo, as categorias "alimentação", "dieta alimentar" e "nutrição" são abordadas em suas acepções socioantropológicas, não restritas à dimensão técnica, podendo diferir das definições que orientam as práticas nos serviços oficiais de saúde. 
alimentar envolvidos no gerenciamento do diabetes empreendido por adoecidos portadores dessa condição crônica e usuários de serviços públicos de atenção básica.

\section{Metodologia, Procedimentos e Técnicas da Pesquisa}

Trata-se de estudo qualitativo, de caráter socioantropológico composto de referencial da representação social, extraído da tradição sociológica francesa, que a entende como construção mental com enraizamentos social e histórico, envolvendo também interpretação e a atribuição de sentido (Herzlich, 1991), sinalizando a ação do sujeito em sua constitutividade, mas sempre compreendida em articulação com o cenário social mais amplo. Na abordagem adotada, as representações sociais articulam-se ao conceito de experiência, de inspiração fenomenológica (Rabelo e col., 1999), porém ampliado e perpassado pelas relações sociais e pelos conteúdos simbólicos e valorativos, que ultrapassam as interações face a face e situacionais, enfocadas por esta última corrente de pensamento sociológico.

Estudos sobre a experiência da doença costumam enfatizar o processo individual de vivência da enfermidade, partindo do ponto de vista dos adoecidos e em situações concretas do mundo da vida (Canesqui, 2007), apresentado como fluxo de eventos, processos corporais e trajetória de vida, que tomam lugar num cenário conectado aos contextos social e cultural e à biografia pessoal, que moldam a condição do adoecido. Ao tomar as representações e a experiência com a dieta alimentar e a alimentação a partir dos relatos dos adoecidos, assume-se a interpenetração entre os termos, relativizando as determinações externas e internas (objetivas e subjetivas, respectivamente) e evitando-se os reducionismos, sejam sociais, culturais ou subjetivos, individuais. As representações sociais sobre a dieta alimentar, alimentação e os alimentos remetem às suas respectivas classificações e significados (dimensão simbólica) e dão, em parte, sustentação às práticas alimentares cotidianas concretas imersas nas condições de vida de grupos sociais (dimensão material) envoltas no processo de gerenciamento do diabetes.

Este artigo é parte dos resultados de uma pesquisa mais ampla sobre as representações sociais e a experiência com diabetes (Barsaglini, 20o6) de pessoas nessa condição, residentes em um município do interior paulista, identificadas pelo cadastro do Hiperdia $^{3}$ e convidadas pela pesquisadora para fazer parte do estudo. Os dados estavam organizados por macrorregião, tendo sido selecionada aquela com maior quantidade de cadastros e maior tempo de presença e intervenção da unidade básica de saúde, pressupondo número suficiente de informantes e de vínculo mais consolidado dos profissionais com a população (pertinente no contexto da pesquisa). Dessa região constavam um centro de saúde organizado pelo modelo tradicional e três unidades de Saúde da Família, entre outros serviços públicos de saúde.

Os critérios de inclusão dos participantes foram: ser de ambos os sexos (para verificar possíveis variações de gênero); com diagnóstico de diabetes do tipo 2 há pelo menos 1 ano (considerado período de familiarização com a nova condição); sem complicações decorrentes da enfermidade e não usuários de insulina (situações que imprimem especificidades no gerenciamento pelas possíveis, conhecidas e rápidas consequências do não seguimento das recomendações); usuário de serviços públicos de atenção básica (local de cadastramento no Hiperdia e onde os casos de diabetes, em sua maioria, deveriam ser acompanhados).

Os dados foram coletados através de entrevistas orientadas por roteiro semiestruturado com temas amplos e preliminares explorados no decorrer dos encontros, que ocorriam na residência dos informantes e incluíam a participação de familiares presentes no domicílio na ocasião, que complementavam informações e lembravam eventos ou detalhes vivenciados, sendo situação prevista no projeto de pesquisa.

O número de participantes foi delimitado pela saturação dos temas e totalizou 28 pessoas com

3 Trata-se do sistema de cadastramento e acompanhamento de hipertensos e diabéticos, previsto pelo "Plano de reorganização da atenção à hipertensão e ao diabetes mellitus”, proposto pelo Ministério da Saúde (Brasil, 2001) e implantado no município em questão desde 2003 . 
diabetes (15 mulheres, 13 homens) e 10 familiares (dois esposos, seis esposas, dois filhos). Eles tinham entre 48 a 79 anos, característica esperada uma vez que o diabetes do tipo 2, em geral, acomete pessoas a partir dos 40 anos.

Todas as entrevistas foram realizadas pelo pesquisador, gravadas e transcritas, e, coerente com a técnica da análise temática, procedeu-se a leitura exaustiva e a categorização dos dados, identificando os temas que denotavam estruturas de relevância, valores de referência ou modelos de comportamentos explícitos ou subjacentes ao discurso (Minayo, 2000; Víctora e col., 200o), que foram cotejados com os dados de outros estudos socioantropológicos sobre o diabetes, a alimentação e a dieta alimentar. Assim, os dados apresentados a seguir foram organizados em três temas amplos sempre remetidos ao processo de gerenciamento do diabetes, a saber: as representações sociais sobre a alimentação, alimentos e dieta alimentar; as compensações das transgressões alimentares; a relação de homens e mulheres com a alimentação, os alimentos e as dietas alimentares.

Observando os princípios éticos, a pesquisa foi e aprovada pelo Comitê de Ética em Pesquisa/Faculdade de Ciências Médicas/Unicamp, conforme recomenda a Resolução $n^{0}$ 196/96 do Conselho Nacional de Saúde sobre pesquisa com seres humanos. Os nomes empregados neste texto são fictícios.

\section{As representações sociais sobre a alimentação, os alimentos e a dieta alimentar no gerenciamento do diabetes}

Nas representações sobre as causas do diabetes expressas pelos informantes, a alimentação figura como fator provocante, além de elemento essencial ao seu controle ou descontrole. Essas explicações remetem à busca pelo sentido da enfermidade e envolvem interpretação baseada em diferentes matrizes de significados e de práticas devido à heterogeneidade cultural própria da sociedade contemporânea apontadas por Guedes (1998).

Nesse sentido, as explicações sobre a origem do diabetes coadunam-se com as noções de causalidade das doenças entre os segmentos populares que são pluricausal e relacional, constituindo-se de domínios distintos, mas vinculados, intercambiantes e não contraditórios, remetendo à compreensão totalizante da doença e distinta do conceito de etiologia, segundo o modelo biomédico, centrado na abstração da doença e nos aspectos biológicos, metabólicos e hereditários.

No fragmento de relato a seguir, cujo depoente é adepto de um segmento religioso, são mobilizados significados religiosos explicativos da enfermidade, combinados com a apropriação de termos da medicina científica, possibilitando ao sujeito uma análise mais globalizante da sua condição, em que a alimentação, a hereditariedade e a punição divina se imbricam na construção causal, não restrita ao plano físico e ao diabetes:

Antes, Adão, Eva não comiam carne: viviam do fruto da terra e das ervas. [...] Hoje sofro as consequências, assumo parte dessa responsabilidade, má alimentação por ignorância e falta de conhecimento na área. Mas trago também a hereditariedade. [...] Não podemos esquecer que o pecado, a desobediência entrou no mundo... o homem foi tentado pelo apetite. [...] Mas a serpente usando o primeiro espiritismo que houve, quando o diabo entrou no seu corpo e a usou como ferramenta. [...] Quando a mulher olhou a serpente que comia o fruto e dizia "Estou comendo, é uma delícia e não estou viva?" Era um animal que falava e despertou a curiosidade e nós morremos pelo apetite $e$ pela curiosidade. Ela aceitou, comeu, não morreu, ficou inteira, mas desobedeceu. [...] Isso trouxe a tragédia da doença também. A morte, a doença, o sofrimento - tudo é consequência. Eu também sou participante e herdeiro desses problemas... (Jonas).

Ao lado desses significados observa-se a importância da percepção das sensações corporais relacionadas e provocadas pelos efeitos da alimentação na suspeita de diabetes, como o "excesso de apetite" e a "falta de saciedade" após as refeições. Assim, as representações sobre as causas do diabetes se apóiam em fatores simultaneamente dependentes ou independentes da vontade do sujeito. Se, por um lado, aqueles fatores que fogem ao seu controle, como os hereditários, também presentes em suas explicações da enfermidade, suavizam o peso da responsabilidade individual pelo problema, por outro lado, o fato de apreciar e consumir muito açúcar 
sugere ser o diabetes uma doença do excesso, da disposição, do gosto e da preferência incontrolável da vontade do sujeito por certos alimentos.

Dessa forma, reforça-se nas representações a intervenção da vontade do sujeito na enfermidade, sob o ponto de vista moral, para evitar transgressões às normas alimentares de não ingerir alimentos excessivamente calóricos e açúcares, segundo as prescrições dietéticas médico-científicas. A falta de controle do sujeito sobre a sua vontade aliada às falhas no dever de cuidar da própria saúde implicam em autopunição, podendo provocar desconfortos morais nos sujeitos (Broom e Whittaker, 2004), como componentes do sofrimento. Essas questões transparecem nos depoimentos:

Eu terminava de almoçar e estava com aquela fome violenta! Minha mulher falou para eu ir ao médico, achando que era diabetes e eu achava que não. Não sentia nada a não ser que andava 100 metros e estava com vontade de ir ao banheiro, a boca ficava ressecada. Fiz o teste na praça e constatou acima de 400 (Cícero).

o sofrimento é consequência de nossas desobediências, má alimentação ou as extravagâncias dos pais e avós e a gente paga um preço. [...] Extravagâncias são o excesso que cometeram em vícios, alimentação errada, excesso de carboidratos. Tudo o que fazemos hoje e fizemos na juventude, reverte na saúde hoje. Uma alimentação não controlada, sem orientação... Quando era criança, jovem, me excedi em alimentos calóricos... [...] Criança gosta de lanches, pão e isso aí já é um início errado, que vai refletir no futuro, acarretando doenças - e aténo presente porque a obesidade pode trazer o diabetes (Jonas).

Ao lado dos excessos representados pelo consumo extra e impositivo de alimentos que agravam ou favorecem o diabetes, figura a combinação inadequada de alimentos nas formas líquidas e sólidas, compondo as explicações dos informantes sobre as causas do diabetes e da obesidade. 0 "comer à vontade" aproxima o homem do estado de natureza colocando-o, no plano das representações, fora da ordem cultural normativa que prescreve o que se deve comer. A subversão das regras alimentares impostas pelas prescrições dietéticas também contrariam as representações do ser humano "livre e natural" (nas representações dos adoecidos) inscrito na natureza, que deve submeter-se ao saber médico-nutricional para controlar a enfermidade, como explica outro entrevistado:

Fiz exame e constou 220 de diabetes, e o médico falou "agora está aqui o seu cardápio, a comida que você vai comer, o que pode ou não comer". [...] Eu sabia o que tinha me deixado daquele jeito - foi muito refresco e nunca tomei adoçante, só usava açúcar. [...] Diabetes é por causa de extravagância: comer bastante carne gordurosa, tomar refrescoe suco demais. Tinha um médico cardiologista que dizia, "nós humanos, ao sentarmos à mesa, temos que deixar o líquido de lado, porque se você comer e tomar suco, refresco, bebida, o seu estômago fica como a uma lavagem..." A pessoa engorda, fica ruim porque isso se faz com porco - quando ele está grandão é colocado sozinho na ceva e é tratado à vontade: o bicho chega a cair deitado de tão gordo. Eu costumava tomar suco no almoço. A diabetes vem disso também... (Cosme).

0 consumo de doces, muito associado à alteração da glicemia e à causa do diabetes como explicam os informantes, é relatado como habitual ou não, antes da sua descoberta. Após o diagnóstico, segundo as representações dos entrevistados do gênero masculino, intensifica-se por um "apetite incontrolável” como uma característica da enfermidade, que se comporta como entidade externa, detentora de vontade própria, que precisa ser alimentada com açúcar. Essa representação pode proporcionar ao sujeito certo conforto moral por eximi-lo da culpa pela transgressão alimentar e negligência com a sua saúde. Brown e Whitaker (2004) citam que as transgressões às escondidas pelos adoecidos diabéticos sugerem a presença de um processo de auto e heterovigilância da conduta alimentar, complementada também pelas explicações do senso comum sobre as necessidades impostas pela doença ao funcionamento/fisiologia do corpo na enfermidade. Relataram os entrevistados:

A mulher às vezes faz um doce e é uma tentação. Quem tem diabetes, o doce parece atrair. Se ela faz brigadeiro e põe na geladeira, eu vou lá e pego 2 ou 3 e como escondido... (Cosme). 
Às vezes sinto muita vontade, porque eu gosto muito de doces sem exceção, e acredito que seja da própria doença que faz a gente sentir essa necessidade. Antes de ter não era tão chegado a doce - tudo que é proibido é um apelo muito forte. [...] Por exemplo, quando a pessoa tem colesterol, ele geralmente, gosta de carne gorda; porque a carne gorda vai alimentar aquela doença. Acho que a própria doença que já convida, exerce uma influência no nosso organismo para que a gente mantenha isso (Jonas).

O tipo e a quantidade de alimentos normatizados pela dieta prescrita são reconhecidos pelos adoecidos como fatores essenciais ao controle do diabetes, mas as ideias e as práticas que possuem sobre eles podem apresentar incongruências com o padrão das prescrições nutricionais, inviabilizando o seu uso, no mundo da vida cotidiana dos adoecidos. No entanto, não seguir à risca as recomendações da dieta alimentar orientada nos serviços oficiais de saúde não impede que adoecidos considerem que controlam a alimentação, sugerindo que o significado de controle lhes é peculiar, de forma que evitam alguns tipos de alimentos e em determinadas ocasiões, mas não se privam totalmente deles. Assim, os adoecidos resistem ou rejeitam as prescrições alimentares dos profissionais de saúde que preconizam parar ou cessar o uso das comidas integradas ao gosto, às escolhas ou aos hábitos alimentares rotineiros.

Para tanto, substituem o imperativo do controle da dieta por entendimentos e práticas de ajustamento dos padrões de comer para prover suas exigências e gostos individuais e da vida social (Garcia, 2005; Naermiratch e Manderson, 2006). Nota-se ideias de flexibilidade e volição expressas pelos termos "manerar"; "ralear"; "diminuir;" "controlar"; "corrigir;" "experimentar, mas não comer”; simbolizando formas de gerenciar a alimentação na condição do diabetes atenuando, portanto, o caráter punitivo das transgressões, com permissibilidade.

Essa distância entre as recomendações, as representações e as experiências no gerenciamento das dietas é sublinhada na linguagem irônica, usada pelos informantes, na qual contrapõem as exigências das restrições da dieta alimentar à valorização da comida abundante que proporciona a sensação de saciedade. Acrescenta-se o contraste entre as representações alimentares eruditas e populares presentes no encontro terapêutico, que embute a desigualdade do saber e da autoridade dos respectivos argumentos, mostrando-se desfavorável àquelas de senso comum, como se entrevê nos depoimentos:

Minha irmã quer que eu vá consultar com a nutricionista para educar sobre o modo de comer, mas já sei o que ela vai falar, então, não vou não! "Não pode comer ovo por causa do colesterol, não pode comer isso e aquilo". Se for ver, então, não tem nada para a gente comer... [...] Quando você fica doente, não pode comer e quando você está com saúde, pode comer... Se você sabe que não pode comer, isso é triste... Porque eu digo ao médico sobre a dieta, "o senhor está certo, não vou dizer que o senhor está errado, está tudo certo", mas tem que controlar, não é assim também. A gente tem fome... O que é que tem comer? [risos] Controlar tudo bem, mas eu pego três colheres e depois ponho mais duas... [risos] Tomar café eles falam, "três bolachas de manhã e leite". Ah, imagine só três bolachas de manhã cedo... Ah, vá... "só porque o senhor quer" - pensei comigo... (Melissa).

Eles passam três colheres de arroz, feijão, verduras, não sei o quê. Falar a verdade, a gente que é forte precisa de comida. E uma vez, porque estava alterado o exame, o médico falou "a senhora deve estar comendo muito queijo, não pode comer queijo, só do branco...". Ah, eu disse "está bom..." Fazer o que, a gente concorda, não vai discutir mas, "muito queijo"... veja só... [risos] (Dulce).

Não como doce: eu só experimento (Celina).

O valor da alimentação e a recusa das restrições alimentares, pelos entrevistados, têm como referência a preferência pela comida cotidiana, composta de alimentos valorizados positivamente como arroz com feijão, carnes vermelhas, macarrão e pão, bem como a abundância da ingestão e a disponibilidade dos componentes básicos das refeições, como arroz com feijão - componente da identidade de ser brasileiro. Além disso, em se tratando da classe trabalhadora, a comida considerada "forte", como o arroz com feijão e a carne tem um valor simbólico por saciar a fome, recuperar e manter a tão solicitada força física corporal, associada às representações de saúde como 
disposição e aptidão para o trabalho (Costa, 1978; Boltanski, 1979; Canesqui, 2005).

Essa relação transparece quando os entrevistados reportam-se ao regime dietético recomendado substituindo alimentos, respeitando seus hábitos alimentares ou restringindo as quantidades de certos alimentos das refeições, que se traduzem nas expressões "não pode comer nada", "é tirado tudo de comer", "não sustenta" ou não suprem as necessidades "para suportar o trabalho pesado" a desempenhar diariamente ou, em casos extremos, a incoerência em seguir um padrão alimentar que pode levar a um estado crítico de debilidade que culminaria com o "morrer de fome".

Dessa forma, a alimentação prescrita e restritiva é avaliada como "insuficiente" ou "inadequada", podendo provocar debilidades física e moral veiculadas nas representações da "magreza" e "fraqueza", em oposição à corpulência e à força, que coincidem com a concepção de saúde (Canesqui, 2005) ligada à importância da alimentação no provimento da disposição para o cumprimento dos compromissos sociais e morais, do sustento e do cuidado com a família, que é valor central para a classe trabalhadora.

Essa questão permeia a representação do tipo de dieta recomendada pelos nutricionistas e médicos por ser "fraca" e incapaz de saciar a fome, favorecendo a "magreza" e a "fraqueza", distanciando-se do padrão de beleza vinculado à força, materializada na corpulência que possibilita o uso de um corpo "forte" no mundo do trabalho. Como relatam:

Para falar a verdade, nós não fazemos muito a dieta, não. Sempre comemos do mesmo jeito. $\varepsilon$ sabe por quê? Conheço pessoas que têm diabetes e fazem aquela dieta rigorosa, e estão caídas... Nossa! Tem que ver! A pessoa diz "só como duas colheres de arroz, não como feijão...”. $E$ mesmo assim, está caída. Por isso é que acho que tem que fazer um pouco de dieta, mas não assim. Com o açúcar, tudo bem em usar o adoçante. Tenho diabetes, quase não uso adoçante e ela nunca chegou a 20o. Quando vou medir está em 1oo, em 95; bem controlada (Dulce).

Resolvi voltar no dia seguinte ao médico depois que comecei o regime e falei "doutor: estou morrendo...". Ele se assustou e perguntou por quê. Expliquei: "porque duas colherinhas de arroz no almoço, duas no jantar, uma de feijão e um pedacinho de carne e salada não está resolvendo... Estou sentindo muita fraqueza...". Ele então receitou uma vitamina para combater a fome. Mas pensei comigo: "eu não vou comprar vitamina, não". [...] Vou chegar em casa, vou pegar umas cinco, seis colheres de arroz, umas três, quatro de feijão, salada à vontade, carne vou comer de frango, de vaca do jeito que vier porque eu estou morrendo! Não vou fazer regime - quatro meses e quase que eu fui! $\varepsilon$ hoje como quase normal (Cosme).

Chegou uma época que ele virou um esqueleto, não foi Jonas? [esposa de Jonas] Nossa! Fiquei horroroso! Parecia um fantasma, um esqueleto ambulante! (Jonas).

A manutenção da força física, que na classe trabalhadora também significa a sobrevivência própria e da família, é possível através do repouso e da alimentação e, sendo assim, parece ilógico ou injusto ser privado deles, podendo gerar recusa ou hesitação diante das recomendações alimentares. A experiência de uma vida de privações materiais no passado e o projeto e esforço para supri-las com o trabalho esfacela-se diante dos impedimentos colocados pela enfermidade, que faz com que, nas palavras da esposa de um informante, "perde-se a noção da vida, porque comendo bem já é duro trabalhar, imagine trabalhar para não poder comer!”.

O fato de trabalhar e ter alimentos disponíveis, mas não estar autorizado a comê-los, sugere uma incoerência desorganizadora não apenas da alimentação habitual, que promove recusas, mas da ordenação social da vida, sobrevivência e trabalho, que são ideias centrais presentes nas representações dos entrevistados sobre a importância da alimentação.

0 poder aquisitivo influencia o consumo dos alimentos dietéticos e "clinicamente" permitidos, mas é insuficiente para explicar o não seguimento e as reformulações alimentares feitas pelo adoecido, que são "intermediadas pelas normas culturais e pela ideologia (formas de pensar socialmente construídas) que cercam os usos, a seleção dos alimentos, a aprendizagem e a socialização do que comer e marcam identidades e particularidades dos grupos sociais" (Canesqui, 2005, p. 169). As incongruências entre as recomendações e as práticas alimentares dos adoecidos sugerem uma oposição à dieta especí- 
fica de um grupo social (do pobre, de quem trabalha, do ser brasileiro), às vezes identificando certos alimentos (verduras, por exemplo) como "coisas", o que se aproxima do que, de acordo com Canesqui (2005), são classificados como "supérfluos" em contraste com o que é considerado "comida básica".

Sob outro ângulo, as restrições alimentares são uma "faca de dois gumes" porque prometem proteger contra danos futuros, mas também provocam uma vida de privações e possíveis julgamentos negativos por outras pessoas com ou sem diabetes, pelo fato de o ato de comer ser um evento social e carregado de significados sociais (Canesqui, 2005). Desse modo, as proibições de comidas valorizadas e dos doces, que são consumidos nas refeições compartilhadas em determinadas ocasiões festivas, podem acarretar ou serem compreendidas como perdas sociais (Broom e Whittaker, 2004), imprimindo traços depreciativos à identidade de pessoas com diabetes (Hopper, 1981).

Diante disso, o sujeito pode optar pelos benefícios sociais do manejo da alimentação, ainda que contrarie as regras da alimentação considerada adequada, pelos profissionais de saúde, para controlar o diabetes. Acrescenta-se que a atual valorização de um estilo de vida saudável, aliada à associação da alimentação ao desenvolvimento ou agravamento das doenças crônicas, impõe um tipo de vida regrada, expondo as pessoas às recomendações de caráter sanitário (Garcia, 2005). Incide, assim, nas regras alimentares, nas representações sobre as adequações e inadequações alimentares, que acompanham as prescrições dietéticas, em que os prazeres de comer são acompanhados por inquietações (Campos, 1982), repreensões e culpa, por serem potencialmente prejudiciais à saúde.

Nesse sentido, a dieta pode ser seguida na medida em que não compromete o desempenho social, caso contrário, serão tomadas liberdades com as prescrições alimentares, visando minimizar seu impacto (Maclean, 1991). É o que ocorre por ocasião da alimentação nas datas especiais e comemorativas (festividades sociais, religiosas, familiares), em geral, marcadas pela refeição compartilhada e diferenciada da alimentação cotidiana e se constituem em ocasiões em que a comida, além de saciar a fome, nutre simbolicamente os elos e as obrigações familiares (Canesqui, 2005). Nessas situações, os adoecidos empreendem "licenças sociais" (Paterson e col., 1998) não se privando dos momentos de sociabilidade e das regras de etiqueta que permeiam a alimentação, suspendendo o padrão da dieta recomendada para o controle da enfermidade, incorrendo em abusos ou extravagâncias, como relatam:

O chato é não participar de festas, aniversários, porque tudo o que é festa é comida. Você vai lá, empurram bolo na gente, tem que pegar, vem refrigerante e se não beber fica chato. Então, échato ficar sem comer, evitar. Agora se a gente vai, não fica de fora e come mesmo... (Nicolau).

Em festa e de fim de semana esqueço a diabetes (Zoraide).

A ideia de "chato" possui vários significados, nesse depoimento, envolvendo o não poder compartilhar da comensalidade; a quebra das regras de etiqueta e de boa educação, que prescrevem a não recusa de comidas e bebidas ofertadas usualmente a convidados, sendo ainda sua evitação uma forma de situar-se fora do grupo e de sentir-se discriminado.

\section{As compensações das transgressões alimentares}

Cientes dos "abusos" (consumo de tipos de alimentos e bebidas não recomendados pelos nutricionistas e médicos) e "exageros" (consumo além do que lhe é recomendado), os adoecidos não deixam de buscar compensações mediante estratégias postas em prática nos dias que antecedem ou que seguem essas transgressões, como verificar a glicemia capilar na segunda-feira ou seguir a dieta com mais rigor, suprimir certos alimentos e tomar chás caseiros específicos. Entre esses últimos estão os preparados com as folhas de plantas como "insulina”, "joão-bolão", "videira”, "pitangueira”, "pata de vaca”, “carambola”, "pau-peva”, "amoreira”, "carqueja”, "boldo do Chile” e a casca de "maracujá", integrantes da medicina caseira.

Em geral, os chás são considerados "bons" e eficazes pelos informantes, por possuírem propriedades terapêuticas menos agressivas ao corpo do que os medicamentos industrializados, pressupondo uma ação com maior grau de harmonia, ou seja, "contém não apenas um, mas vários princípios ativos que interagem entre si, equilibrando-se numa totalida- 
de que não pode ser desmembrada sem prejuízo" (Queiroz, 2003, p. 153).

Além disso, baseados em conhecimentos tradicionais do senso comum, referem benefícios por estimular funções (do rim/filtro do sangue que pela micção elimina os resíduos nocivos ou excessos do sangue, inclusive o açúcar); por apresentar sabor amargo ("boldo do Chile", "carqueja”) que combate o açúcar, embutindo uma reinterpretação do princípio alopático pelo par oposto amargo/doce, além de "refinar o sangue e acertar o fígado", que se acredita sobrecarregado e prejudicado pelos remédios consumidos. Nesse último caso, a lógica operante não seria a do contrário, mas a da semelhança, lembrando a relação do fel/bílis com o amargo do chá.

A utilização do chá como recurso terapêutico pode ser regular ou pontual após as licenças sociais, ao perceberem sensações que atribuem à alteração da glicemia, bem como nos dias antecedentes à realização de exames médicos. Esses procedimentos significam o "não descuidar" do diabetes, não ser negligente e, consequentemente, não ser reprovado por si mesmo, por outras pessoas e pelos profissionais de saúde em relação à sua saúde, já que considerável parcela da responsabilidade pelo controle do diabetes recai moralmente sobre o indivíduo, segundo as representações dos profissionais de saúde. Como referem:

Tenho há muito tempo um pé dessa planta chamada insulina, no quintal. Mas não pode tomar sempre, é só de vez em quando. Uns tempos, assim, antes de fazer exames... [risos] (Dulce).

Quando a gente faz o testinho e dá baixa, come alguma coisinha ou toma água adoçada. Se estiver alta toma boldo do Chile ou esse frasquinho que compro na farmácia - dose única - e é amargo que só vendo... (marido de Hélia).

Por fim, vale ressaltar as representações religiosas que evocam a interferência divina como força suprema, pertencendo a Deus a decisão final sobre as condições de saúde, doença e cura. Nessas representações, Deus pode fazer retornar ou manter a saúde; castigar com doenças, fortalecer para tolerar as dores sendo fonte de resignação, solução ou atenuação ante o sofrimento (Ibáñez-Novión, 1974). No caso de seguir ou não o regime alimentar no diabetes esse poder divino de intermediação e decisão pode operar em função (punição, castigo) ou em detrimento (graça) da conduta do sujeito, como expressam os excertos:

Diabetes é grave se não for controlada e também pela graça de Deus, porque eu não seguia dieta e nunca tive complicações e minha irmã, também diabética, é cega. Deus me guardou... (Leonor).

Tenho diabetes, quase não uso adoçante, e ela nunca chegou a 20o. [...] Então, eu falo: nunca usei disso tudo aí e, graças a Deus, está boa. Irisos] Agora não sei se é por causa da fé, porque a fé adianta bastante. [...] eu alcancei uma graça: estava com 180 de diabetes e fui na igreja de nossa Senhora dos Prazeres, com o grupo de oração, e recebi essa graça - nunca mais ela subiu. Faz mais de 10 anos e eu como arroz, feijão, pão - que eu gosto muito... (Dulce).

Então, no meu caso, eu pus na cabeça: o que tiver que ser, será Não tenho que sofrer agora, porque Deus está cuidando de mim, então... Tenho que fazer a minha parte, tenho consciência disso, mas não me desespero. (Rosa).

Esse "sincretismo terapêutico" (Camargo Júnior, 2003) envolvido no gerenciamento do diabetes sugere uma compreensão mais totalizante da enfermidade e uma forma de resistência à sua abordagem reducionista, em termos biológicos, devido à unidade corpo/espírito que rege as ideias de doença e cura na classe trabalhadora (Loyola, 1984) que, à maneira de um mosaico de opções, é sintetizado no relato:

Tomo chás amargos como de carqueja que ébom. [...] À noite estou nervosa e, então, rezo e depois tomo o calmante que o cardiologista passou. Aí durmo... (Serena).

\section{A relação de homens e mulheres com a alimen- tação, os alimentos $e$ as dietas alimentares no gerenciamento do diabetes}

0 padrão alimentar é também crivado pela variável de gênero, a começar que a alimentação, em geral, de domínio feminino fica sob o controle das mulheres que são responsáveis pelo gerenciamento da casa e da comida (Canesqui, 2005).

Quanto ao tipo de alimentos, distingue-se a rela- 
ção das mulheres e dos homens com as comidas e as bebidas doces. Os últimos, quando referem à vontade de comê-los, justificam-na por ser própria do diabetes (uma imposição da enfermidade), intensificada após o diagnóstico médico, que reconhece a doença, facultando-lhes identificar-se socialmente como doentes. Já as mulheres às quais, socialmente, é mais compreensível assim se definirem, dispensam o argumento da vontade de comer doces, imposta pelo diabetes, afirmando que sempre gostaram deles e não conseguem controlar sua vontade de comê-los, não podendo "passar sem doce".

As carnes, as comidas gordurosas e com sabores acentuados estão mais associados simbolicamente ao masculino, enquanto os doces, que se enquadram na categoria de “'alimentos supérfluos', opondo-se à comida propriamente dita (arroz com feijão e mistura), são secundários para os adultos e adequados para as mulheres, idosos e crianças, integrados à aprendizagem do comer, mediante o processo de socialização" (Canesqui, 2005, p. 185). A presença do doce no universo feminino pode ser lembrada na expressão "bebida de mulher", para se referir às combinações adocicadas, suaves e com pouco ou nenhum teor alcoólico ou nas bebidas açucaradas (refrigerante, licor, batida, ponche, champanhe, coquetel de frutas), reconhecidamente mais apropriadas e apreciadas pelos paladares "delicados" e femininos.

A recusa em se sujeitar às normas alimentares prescritas para o controle do diabetes está presente nos depoimentos das mulheres, porém é mais proeminente nos relatos dos homens: se para elas seguir as recomendações dirige-se ao controle da enfermidade, para eles parece significar ter a vida controlada. Um informante do gênero masculino refere que com o diabetes tudo "ficou censurado" e que "cortou as regalias”, em alusão à imposição de normas para comer que não devem ser transgredidas e cerceiam "a liberdade" das escolhas alimentares. Além disso, é a mulher quem controla a alimentação na casa e as comidas destinadas ao marido e aos filhos.

Em outro depoimento, a frase "ilha cercada de proibição de todos os lados”, é a representação masculina de ser portador de diabetes e submetido às restrições alimentares, calcada na ideia de segrega- ção e falta de liberdade de escolha alimentar, levando o sujeito a isolar-se por se ver tolhido de vivenciar plenamente a sociabilidade em torno da alimentação ou das bebidas, que reforça os vínculos sociais.

Admite-se que a socialização diferenciada entre homens e mulheres pode delimitar e interferir na experiência do diabetes. Todavia, "as diferenças merecem ser relativizadas pelo cotejamento com as reais circunstâncias e localização particular de cada sujeito no seu grupo" (Schraiber e col., 2005, p. 15) e contexto, como forma de evitar reduzir as análises apenas a traços ou características polarizadas.

Assim, a flexibilidade nas práticas dietéticas é influenciada por fatores materiais do cenário social imediato (interações interpessoais, circunstâncias diárias) e mais amplo (contexto político, econômico) expresso pela oferta, acesso e distribuição dos alimentos, bem como por fatores simbólicos como as "ideias sobre os alimentos, as crenças nas suas propriedades e efeitos que os acompanham, envolvendo valores sociais, noções de moralidade, comportamentos apropriados entre os distintos grupos de idades e gênero, permeado ainda pela identidade social, relações com o corpo e o gosto" (Canesqui, 2005, p. 169), que são postos em interação na vida cotidiana.

\section{Conclusões}

Os referenciais socioantropológicos das representações sociais e da experiência da enfermidade, empregados no estudo, mostraram-se apropriados à compreensão da participação das ideias e significados simbólicos que cercam a alimentação, sempre confrontados com as dietas alimentares orientadas no gerenciamento do diabetes, podendo ser aplicados a outras condições crônicas, desde que observadas as suas especificidades.

O padrão alimentar empreendido pelos adoecidos é um processo complexo e multifacetado que compatibiliza experiência e representações, entre as quais se estabelece uma relação complementar e de influência circular, não sendo representações e experiências isoladas ou opostas, mas integradas no gerenciamento da enfermidade.

Apesar de abranger a experiência, o gerencia- 
mento não se deduz, mas orienta-se em parte pelas representações sobre a saúde, a doença, o diabetes e os componentes do seu manejo - como o alimento, a alimentação e as dietas, enfocadas neste artigo. Sob esse ângulo, além de obstáculos materiais de acesso aos alimentos recomendados é comum a dieta orientada conflitar com os padrões e normas culturais que informam as práticas alimentares do grupo social de pertença do adoecido, em relação à escolha do quê, quanto e quando (tipo, quantidade, ocasião) comer. Observam-se recorrências nos valores que, em parte, orientam e sustentam as ideias e práticas alimentares empreendidas pelos adoecidos quando abordadas pela homogeneidade forjada na dimensão macroanalítica, mas que apresentam singularidades quando analisadas em cada grupo (homens, mulheres) nas situações cotidianas, ainda que seja condição para sua compreensão remetê-las àquele plano mais amplo.

Dessa forma, o gerenciamento se insere na totalidade da vida sendo que o adoecido empreende ajustes e conciliações nas recomendações dietéticas como estratégia para controlar o diabetes em vez de ser controlado, orientando-se nas microdecisões diárias para contornar os efeitos desfavoráveis da enfermidade em função das demandas não médicas e dos aspectos significativos e prioritários da vida cotidiana, viabilizando o viver com e apesar da condição crônica. Entre os efeitos desfavoráveis, pode haver a imputação de traços depreciativos ao adoecido pelos elementos da intervenção como a dieta restritiva e diferenciada que o classificam como diferente e dão visibilidade ao diabetes que, em si, não é estigmatizante.

Se no plano material a alimentação guarda uma função vital e é influenciada pela desigualdade na distribuição de recursos nos diferentes grupos sociais, no plano simbólico ela é perpassada por representações, normas e valores ativados cotidianamente, diversificados no espaço e no tempo, isto é, elas são flexíveis e mutáveis. Nesse sentido, a alimentação está presente no gerenciamento do diabetes como elemento central tanto para a compreensão de sua origem/causa, como para explicar o grau de controle sobre a enfermidade e, nesse processo as representações sociais (da alimentação, da saúde, da doença e os seus respectivos desdobramentos). significam e são significadas no campo da experiência da enfermidade, influenciando-se reciprocamente.

Nota-se que os adoecidos não são passivos diante das múltiplas influências e referências disponíveis na sociedade contemporânea para lidar com a alimentação no gerenciamento do diabetes, (re)interpretando e ajustando conceitos e recomendações nutricionais. Na singular trajetória de vida do adoecido há maneiras individuais e coletivas que interferem no gerenciamento da enfermidade, entrecruzando elementos culturais e sociais, estruturais e subjetivos, materiais e simbólicos, historicamente construídos que informam, delimitam e imprimem sentido à prática alimentar dos distintos grupos sociais, transcendendo o plano individual e situacional das vivências e representações dos adoecidos com diabetes.

Por esta razão, os estudos socioantropológicos contribuem para a compreensão dos elementos presentes nas microdecisões do gerenciamento da enfermidade, que incluem as dietas alimentares, apontando para sua complexidade e os limites das imposições normativas e prescritivas do saber e das práticas médica e nutricional. Considerando haver uma diferença entre o paciente ideal (cooperativo, aquiescente, obediente, passivo e seguidor) e o sujeito reflexivo, que reinterpreta as prescrições alimentares e age em coerência com sua experiência corporal, os conhecimentos prévios, os contextos e as situações cotidianas em que a enfermidade é vivenciada, são requeridas contínuas negociações junto aos adoecidos, constituindo-se em desafio importante no controle e na capacitação para o autocontrole do sofrimento e restrições de vida impostas pela condição crônica do diabetes.

\section{Referências}

ADAM, P.; HERZLICH, C. Sociologia da doença e da medicina. Bauru-SP: EDUSC; 2001. 144p.

ANDERSON, J. M. Women's perspectives on chronic illness: ethinicity, ideology and restructuring of life. Social Science \& Medicine, Oxford, New York, v. 33, n. 2, p. 101-113, 1991. 
BARSAGLINI, R. A. Pensar, vivenciar e lidar com o diabetes. 2006. Tese (Doutorado em Saúde Coletiva) - Programa de Pós-Graduação em Saúde Coletiva, Faculdade de Ciências Médicas, Universidade de Campinas, Campinas, 2006. Disponível em: <http://libdigi.unicamp.br/ document/?code=vllsooo4o6o44>. Acesso em: 12 maio 2009 .

BARSAGLINI, R. A. Análise socioantropológica da vivência do diabetes. Interface - Comunicação, Saúde, Educação, Botucatu, SP, v. 12, n. 26, p. 56377, jul.-set. 2008.

BOLTANSKI, L. As classes sociais e o corpo. Rio de Janeiro: Graal; 1979. 191 p.

BRASIL. Ministério da Saúde. Secretaria de Políticas de Saúde. Plano de reorganização da atenção à hipertensão arterial e ao diabetes mellitus. Brasília: Ministério da Saúde, 2001. 26 p. Disponível em: < http://dtr2oo4.saude.gov.br/dab/ hipertensaodiabetes/publicacoes.php >. Acesso em: 22 ago. 2008.

BROOM, D.; WHITTAKER, A. Controlling diabetes, controlling diabetics: moral language in the management of diabetes type 2. Social Science \& Medicine, Oxford, New York, v. 58, n. 11, p. 23712382, june 2004.

CAMARGO JÚNIOR, K. R. Biomedicina, saber e ciência: uma abordagem crítica. São Paulo: Hucitec, 2003. 195 p.

CAMPOS, M. S. Poder, saúde e gosto: um estudo antropológico acerca dos cuidados possíveis com a alimentação e o corpo. São Paulo: Cortez, 1982.

CANESQUI, A. M. Estudos socioantropológicos sobre os adoecidos crônicos. In: CANESQUI, A. M. (org.) Olhares socioantropológicos sobre os adoecidos crônicos. São Paulo: Hucitec- FAPESP, 2007. p. 19-52.

CANESQUI, A. M. Mudanças e permanências da prática alimentar cotidiana de famílias de trabalhadores. In: CANESQUI, A. M.; GARCIA, R. W. D. (org.). Antropologia e Nutrição: um diálogo possível. Rio de Janeiro: Ed. FIOCRUZ, 2005. p.167210.
COHEN, M. Z. et al. Explanatory models of diabetes: patient practitioner variation. Social Science \& Medicine, Oxford, New York, v. 38, n. 1, p. 59-66, jan. 1994 .

CONRAD, P. The meaning of medications: another look at compliance. Social Science \& Medicine, Oxford, New York, v. 20, n. 1, p. 29-37, 1985.

COSTA, A. M. Riqueza de pobre: um estudo em antropologia da saúde. 1978. 168 f.

Dissertação (Mestrado) - Instituto Central de Ciências Humanas da Universidade de Brasília, Universidade de Brasília, Brasília, 1978.

FRANKENBERG, R. Medical Anthropology and development: a theorical perspective. Social Science \& Medicine, Oxford, New York, v. 14B, n. 4, p. 197-207, nov. 1980.

GARCIA, R. W. D. Alimentação e saúde nas representações e práticas alimentares do comensal urbano. In: CANESQUI, A. M.; GARCIA, R. W. D. (org.). Antropologia e Nutrição: um diálogo possível. Rio de Janeiro: FIOCRUZ, 2005. p. 211-25.

GUEDES, S. Os casos de cura divina e a construção das diferenças. Horizontes Antropológicos, Porto Alegre, v. 4, n. 9, p. 9-29, 1998.

HERZLICH, C. A problemática da representação social e sua utilidade no campo da doença. Physis - Revista de Saúde Coletiva, Rio de Janeiro, v. 1, n. 2, p. 23-36, 1991.

HOPPER, S. Diabetes as a stigmatized condition: the case of low-income clinic patients in the United States. Social Science \& Medicine, Oxford, New Cork, v. 15B, n. 1, p. 9-11, jan. 1981.

IBÁÑEZ-NOVIÓN, M. A. El cuerpo humano, la enfermidad e su representación social. 1974. 188 f. Dissertação (Mestrado em Antropologia Social).

- Programa de Pós-Graduação em Antropologia Social, Museu Nacional da Universidade Federal do Rio de Janeiro, Rio de Janeiro, 1974.

LOYOLA, M. A. Médicos e curandeiros: conflito social e saúde. São Paulo: Difel, 1984. 198p.

MACLEAN, H. M. Patterns of diet related self-care in diabetes. Social Science \& Medicine, Oxford, New York, v. 32, n. 6, p. 689-696, 1991. 
MINAYO, M. C. S. O desafio do conhecimento: pesquisa qualitativa em saúde. São Paulo: HucitecABRASCO; 2000. 269 p.

NAEMIRATCH, B.; MANDERSON, L. Control and adherence: living with diabetes in Bangkok, Thailaind. Social Science \& Medicine, Oxford, New York, v. 63, n. 5, p. 1147-1157, sept. 2006.

OMS - Organização Mundial da Saúde. Cuidados inovadores para condições crônicas: componentes estruturais de ação - relatório mundial. Brasília: Organização Mundial da Saúde, 2003.

PATERSON, B. L.; THORNE, S.; DEWIS, M.

Adapting to and managing diabetes. Image: Journal of Nursing Scholarship, v. 3o, n. 1, p. 57-62, 1998.

QUEIROZ, M. S. Saúde e doença: um enfoque antropológico. Bauru: EDUSC, 2003. 228 p.

RABELO, M. C.; ALVES, P. C. B.; SOUZA, I. M. A. (org.). Experiência de doença e narrativa. Rio de Janeiro: FIOCRUZ, 1999.

SCHRAIBER, L. B.; GOMES, R.; COUTO, M. T. Homens e saúde na pauta da Saúde Coletiva. Ciência \& Saúde Coletiva, Rio de Janeiro, v. 10, n. 1, p. 7-17, jan.-mar. 2005.

THORNE, S.; PATERSON, B.; RUSSEL, C. The structure of everyday self-care decision making in chronic illness. Qualitative Health Research, Newbury Park, CA, v. 13, n. 10, p. 1337-1352, dec. 2003.

VÍCTORA, C. G.; KNAUTHK, D. R.; HASSEN, M. N. Pesquisa qualitativa em saúde: uma introdução ao tema. Porto Alegre: Porto Editorial, 2000. 132 p. 